\title{
The impact of in-stent neoatherosclerosis on long-term clinical outcomes: an observational study from the Kobe University Hospital optical coherence tomography registry
}

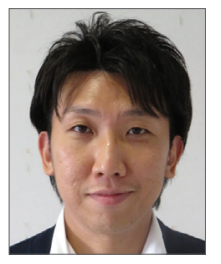

Masaru Kuroda, MD; Hiromasa Otake*, MD; Toshiro Shinke, MD; Tomofumi Takaya, MD; Masayuki Nakagawa, MD; Tsuyoshi Osue, MD; Yu Taniguchi, MD; Masamichi Iwasaki, MD; Ryo Nishio, MD; Hiroto Kinutani, MD; Akihide Konishi, MD; Ken-ichi Hirata, MD

Division of Cardiovascular Medicine, Department of Internal Medicine, Kobe University Graduate School of Medicine, Hyogo, Japan

This paper also includes supplementary data published online at: http://www.pcronline.com/eurointervention/108th_issue/224

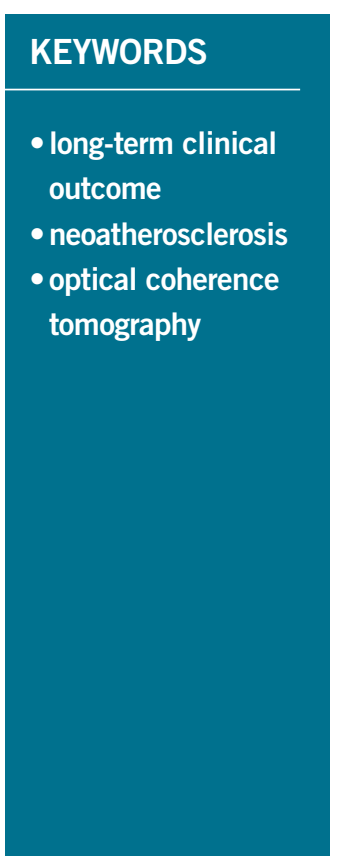

\begin{abstract}
Aims: Although pathological studies have indicated the development of neoatherosclerosis (NA) after stenting, its risk factors and impact on future clinical events remain unclear. We aimed to clarify the possible risk factors for NA development and to evaluate the impact of NA in a large Japanese observational OCT database of patients with coronary heart disease.
\end{abstract}

Methods and results: One hundred and seventy-five consecutive patients (314 lesions) who underwent OCT examination $>1$ year after bare metal or drug-eluting stent implantation were enrolled. We assessed the presence of NA by follow-up OCT and compared adverse clinical events between NA+ and NA- patients. Forty-six patients had NA at the follow-up OCT. These patients had higher low-density lipoprotein (LDL) cholesterol and C-reactive protein (CRP) levels at follow-up. In multivariate logistic analysis, LDL cholesterol and CRP levels at follow-up were independently associated with the presence of NA (odds ratio [OR]: 1.022, $\mathrm{p}=0.008$, OR 1.022, $\mathrm{p}=0.001$, respectively). Moreover, patients with NA had a higher incidence of major adverse cardiac events (MACE) at follow-up. Multivariate Cox hazard analysis showed that the presence of NA was an independent risk factor for MACE (hazard ratio: 2.909, p=0.012).

Conclusions: High LDL cholesterol and CRP levels may be risk factors for NA development in patients treated with coronary stents. Moreover, the presence of NA was independently associated with MACE, suggesting the need for careful clinical follow-up of these patients.

\footnotetext{
*Corresponding author: Kobe University Graduate School of Medicine, Department of Cardiology, 7-5-1 Kusunoki-cho, Chuo-ku, Kobe, Hyogo, 650-0017, Japan. E-mail: hotake@med.kobe-u.ac.jp
} 


\section{Abbreviations}

$\begin{array}{ll}\text { CAD } & \text { coronary artery disease } \\ \text { CRP } & \text { C-reactive protein } \\ \text { DES } & \text { drug-eluting stent } \\ \text { LDL } & \text { low-density lipoprotein } \\ \text { MACE } & \text { major adverse cardiac events } \\ \text { MI } & \text { myocardial infarction } \\ \text { NA } & \text { neoatherosclerosis } \\ \text { OCT } & \text { optical coherence tomography } \\ \text { PCI } & \text { percutaneous coronary intervention } \\ \text { TLR } & \text { target lesion revascularisation }\end{array}$

\section{Introduction}

Drug-eluting stent (DES) use has dramatically reduced the midterm incidence of target lesion revascularisation (TLR) by suppressing acute-phase excessive neointima proliferation that occurs in response to stenting. However, late-phase clinical events, including late stent thrombosis and delayed restenosis, termed as late DES failure, have been proposed as potential concerns after first- and second-generation DES implantation ${ }^{1,2}$. Emerging evidence has suggested the involvement of atherogenic progression within neointima, termed as neoatherosclerosis (NA), in these events $^{3}$.

Recently, Kang et al demonstrated the ability of optical coherence tomography (OCT) to detect atherogenic changes within neointima and showed a high incidence of NA with late DES failure $^{4}$. However, the lack of information on NA prevalence in nonevent cases, and its relation with long-term clinical events, limits the clinical value of NA detection by OCT in clinical settings,

Here, we aimed to clarify the possible risk factors for NA development and to evaluate the impact of NA in a large Japanese observational OCT database of patients with coronary artery disease.

\section{Methods}

\section{PATIENT POPULATION}

The Kobe University Hospital OCT registry is a single-centre registry of consecutive patients who underwent OCT of the coronary arteries between July 2005 and February 2013. Any patient who underwent OCT was eligible for the registry. During this period, we performed OCT for the following reasons: 1) planned follow-up coronary angiography (CAG) and OCT as routine stent follow-up or due to other study protocols, regardless of symptoms, 2) evidence of myocardial ischaemia such as silent myocardial ischaemia, stable angina, or acute coronary syndrome, or 3) planned follow-up angiography for other stent segments. Exclusion criteria for OCT were: 1) anatomically unsuitable target artery for OCT according to previously described criteria ${ }^{5}$, 2) apparent congestive heart failure, 3) renal insufficiency with baseline creatinine level $\geq 2.0 \mathrm{mg} / \mathrm{dL}, 4$ ) no written informed consent from the patient. Among 426 patients enrolled into this registry during this period, 175 consecutive patients (314 lesions) who met the following criteria were enrolled into the present study: 1) patients treated with bare metal stents (BMS), sirolimus-eluting stents (SES) (CYPHER ${ }^{\circledR}$; Cordis, Johnson and Johnson, Miami Lakes, FL, USA), paclitaxel-eluting stents (PES) (TAXUSTM; Boston Scientific, Marlborough, MA, USA), or everolimus-eluting stents (EES) (XIENCE V ${ }^{\circledR}$; Abbott Vascular, Santa Clara, CA, USA, or Promus ${ }^{\mathrm{TM}}$; Boston Scientific), and 2) patients who underwent $\mathrm{CAG}$ and OCT examination $>1$ year after stent implantation (Figure 1). NA, defined as lesions with lipid-laden neointima, neointima with calcification, a thin-cap fibroatheroma-like neointima or neointimal rupture ${ }^{4,6,7}$ (Figure 2), was assessed on the follow-up OCT and patients were subdivided according to the presence or absence of NA (NA+ group and NA- group, respectively) (Figure 1).

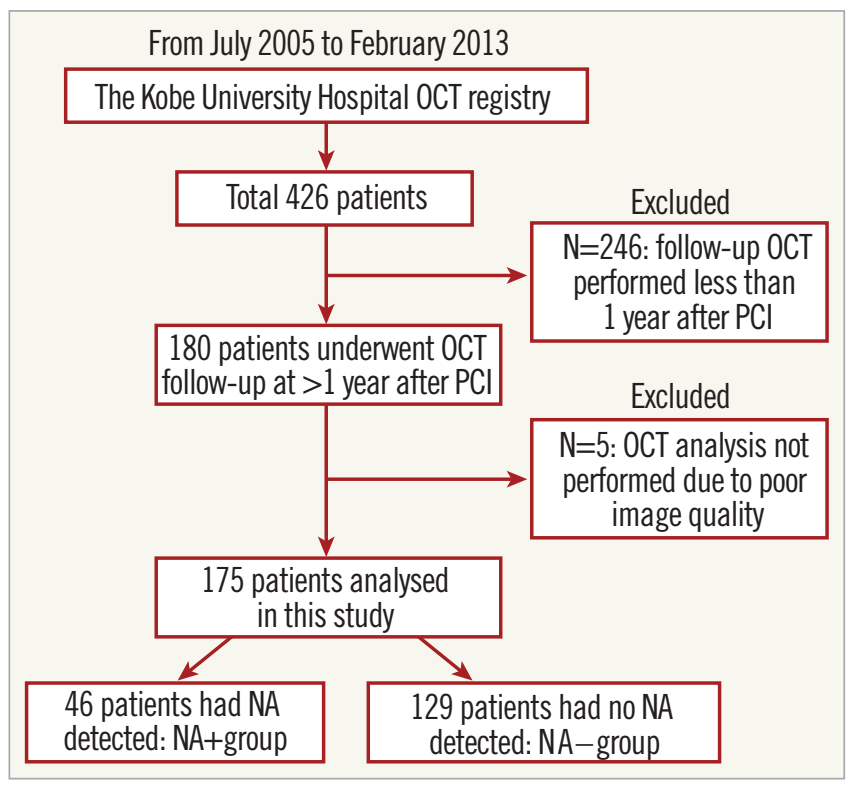

Figure 1. Study population.

The percutaneous coronary intervention procedure was performed with intravascular ultrasound guidance. All patients were receiving aspirin $(100 \mathrm{mg} /$ day $)$. Patients also received ticlopidine (200 mg/day) or clopidogrel (75 mg/day) for at least two weeks after BMS implantation or for at least three months after DES implantation. Blood samples were collected before cardiac catheterisation after overnight fasting for 10 to 12 hours. This study was approved by the ethics committee of Kobe University and was performed according to the guidelines of the Declaration of Helsinki. All study patients provided written informed consent to undergo the follow-up OCT and for enrolment into the study.

\section{OCT EXAMINATION}

Both the time-domain OCT system (M2 Cardiology Imaging System; LightLab Imaging, Westford, MA, USA) and the frequency-domain OCT system (C7-XR TM OCT Intravascular Imaging System; St. Jude Medical, St. Paul, MN, USA) were used in the present study. OCT examination was performed, as previously reported $^{8}$. In cases evaluated by the time-domain OCT system, 

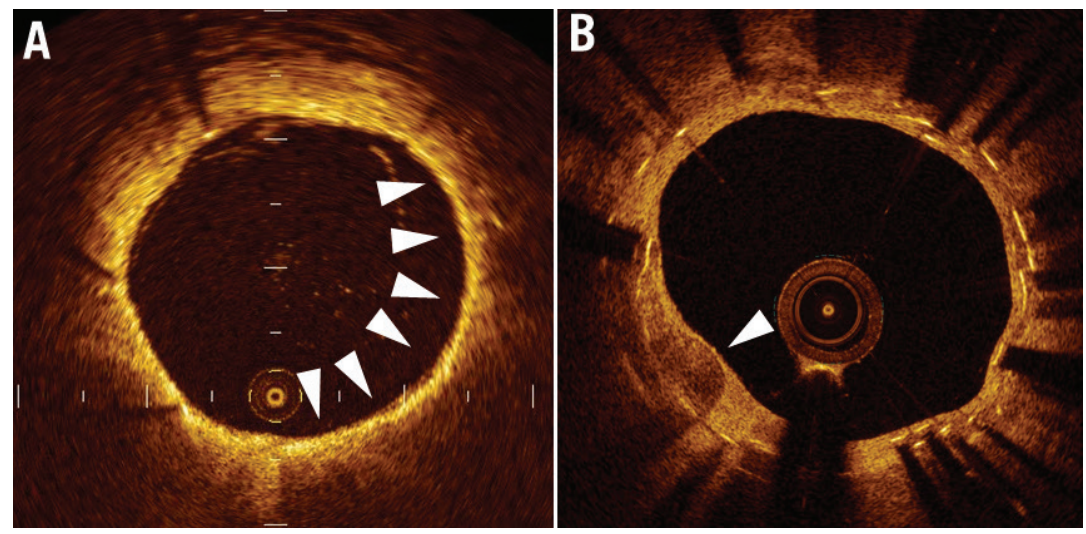

Figure 2. Representative OCT images. Representative optical coherence tomographic images of neointimal tissue. A) Lipid-laden neointima (arrows). B) Neointima with calcification (arrow).

a 0.016-inch OCT catheter (ImageWire; LightLab Imaging) was advanced to the distal end of the stented lesion through an occlusion balloon catheter (Helios ${ }^{\mathrm{TM}}$; LightLab Imaging). The occlusion balloon was inflated to $0.5 \mathrm{~atm}$ at the proximal site of the stented lesion, followed by an infusion of lactated Ringer's solution into the coronary artery from the distal tip of the occlusion balloon catheter at 0.5 to $0.7 \mathrm{~mL} / \mathrm{s}$, to clear the area of blood. The entire stented length of the lesion was then imaged using an automatic pullback system moving at $1 \mathrm{~mm} / \mathrm{s}$. In cases evaluated with the frequency-domain OCT system, a C7 Dragonfly ${ }^{\mathrm{TM}}$ catheter (LightLab Imaging) was advanced to the distal end of the stented lesion over a 0.014 -inch guidewire, followed by an infusion of contrast medium into the coronary artery from the guiding catheter at $3.5 \mathrm{~mL} / \mathrm{s}$, which served as a flush to clear the area of blood. The entire stented length was then imaged using an automatic pullback system moving at $20 \mathrm{~mm} / \mathrm{s}$.

\section{OCT ANALYSIS}

All OCT images were analysed at every frame in stents by two independent investigators, who were blinded to the angiographic and clinical findings, using Off-line Review Workstation software. When discordance occurred between observers, a consensus reading was obtained. The criteria for the diagnosis of NA were lesions with lipid-laden neointima, neointima with calcification, a thin-cap fibroatheroma-like neointima or neointimal rupture ${ }^{7}$. Lipid-laden neointima was defined as a signal-poor region with diffuse borders, and neointima with calcification was defined as a well-delineated, signal-poor region with sharp borders ${ }^{9}$. A thincap fibroatheroma-like neointima was defined as neointima with a fibrous cap thickness at the thinnest part $<65 \mu \mathrm{m}$ and an angle of lipid-laden neointima $>180^{4,6,9}$. Neointimal rupture was a break in the fibrous cap that connected the lumen with the underlying lipid pool. Microvessels were defined as well-delineated low backscattering structures $<200 \mu \mathrm{m}$ in diameter showing a trajectory within the vessel ${ }^{10}$. Intraobserver and interobserver agreements for the detection of NA were within the acceptable range (intraobserver, kappa $=0.946$; interobserver, kappa $=0.890$ ).

\section{OUTCOME VARIABLES AND DEFINITIONS}

Long-term clinical outcome data (mean 50.9 7.7 months) were obtained by reviewing outpatient records or telephone interview. The primary outcomes were death, myocardial infarction (MI), stent thrombosis according to the ARC definition ${ }^{11}$, clinically driven TLR, and MACE (cardiac death, MI, and TLR) $>1$ year after stent implantation. All deaths were considered cardiac-related unless an unequivocal non-cardiac cause could be established. MI was considered in cases where the cardiac enzyme levels (troponin or myocardial band fraction of creatine kinase) were greater than the upper limit of the normal value ${ }^{12}$. All events were carefully verified and adjudicated by independent clinicians.

\section{STATISTICAL ANALYSES}

Qualitative data are presented with frequencies, and quantitative data are shown as mean values \pm SD. For continuous variables, comparisons between two groups were performed using a twotailed, unpaired t-test or Wilcoxon test. Discrete variables are presented as percentages, and comparisons were performed by chisquare analysis or Fisher's exact test. Logistic regression analyses were performed to identify independent predictors of the presence of NA. Survival curves were constructed using Kaplan-Meier estimates and compared with the log-rank test. Hazard ratios and 95\% confidence intervals (CI) were calculated by means of the Cox proportional hazards regression model. Variables which showed a statistically significant effect on event-free survival in the univariate analyses were entered in a multivariate Cox proportional hazards model using a backward stepwise selection to obtain the final model. At each step, the least significant variable was discarded from the model, until all variables in the model reached a $p$-value of $<0.25$. A probability value (p) of $<0.05$ was considered statistically significant. The value of CRP was multiplied by 100 before calculating both logistic and Cox proportional analysis. To assess intraobserver and interobserver variabilities, categorical data were compared with the kappa test of concordance. Analyses were performed using commercially available software, SPSS, Version 20 (IBM Corp., Armonk, NY, USA). 


\section{Results}

\section{PATIENT CHARACTERISTICS}

Between July 2005 and February 2013, 175 patients were enrolled. NA was identified in 46 patients at follow-up OCT (NA+ group). The remaining 129 patients did not exhibit NA (NA- group). The mean follow-up time from stent implantation to the OCT followup was significantly longer in the NA+ than in the NA- group. There were no significant differences between the groups in medications or laboratory data at the OCT follow-up, although the rate of statin usage was significantly lower, and CRP and LDL cholesterol levels were significantly higher in the NA+ group (Table 1).

\section{LESION CHARACTERISTICS}

Of 314 lesions, 54 were identified as NA at the follow-up OCT. Compared with lesions without NA, those lesions with NA had a significantly longer follow-up duration of OCT and a higher frequency of type B2/C lesions (Table 2).

\section{THE RISK FACTORS OF NEOATHEROSCLEROSIS}

All patient characteristics and laboratory data were analysed by univariate and multivariate logistic regression analysis to clarify patient-based risk factors for the development of NA (Table 3). Univariate analysis showed that higher CRP and LDL cholesterol levels were positively associated with NA, whereas statin use was negatively associated with the presence of NA. Multivariate analysis revealed that CRP and LDL cholesterol levels were independently associated with the presence of NA.

Receiver operating characteristic (ROC) curves showed that the optimal cut-off value of CRP for the presence of NA was $0.055 \mathrm{mg} / \mathrm{dL}$, with a sensitivity of $63.6 \%$ and a specificity of $73.9 \%$ (area under the curve [AUC]: $0.73,95 \% \mathrm{CI}$ : $0.65-0.81$ ), and that of LDL cholesterol for the presence of NA was $86 \mathrm{mg} / \mathrm{dL}$, with a sensitivity of $57.4 \%$ and a specificity of $71.7 \%$ (AUC: 0.64 , 95\% CI: 0.55-0.73) (Figure 3A). The patients with CRP and LDL cholesterol levels of $>0.055 \mathrm{mg} / \mathrm{dL}$ and $>86 \mathrm{mg} / \mathrm{dL}$, respectively, had an 18.8-fold higher risk of NA progression compared to those who did not fulfil both criteria (Figure 3B).

Lesion-specific data were also compared between the $\mathrm{NA}+$ and NA- groups to investigate potential lesion-specific risk factors for NA progression (Appendix Table 1). Univariate analysis showed that longer follow-up duration of OCT and the high frequency of lesion type B2/C were positively associated with NA. In multivariate analysis, follow-up duration of OCT and frequency of lesion type B2/C were independently associated with the presence of NA.

\section{CLINICAL OUTCOMES}

In the overall population, six patients suffered from $\mathrm{MI}(\mathrm{NA}+, \mathrm{n}=4$ vs. NA-, n=2). All of the MI in the NA+ group occurred due to target lesion occlusion, while one out of two in the NA- group had an MI of a non-target lesion. Three patients in the NA+ group died of cardiac death: one patient died of possible ST, one patient of definite ST related to the target lesion and one patient of heart failure, whereas no patient in the NA- group experienced cardiac
Table 1. Baseline clinical characteristics.

\begin{tabular}{|c|c|c|c|c|}
\hline \multicolumn{2}{|c|}{ Variable } & $\begin{array}{c}N A+ \\
(n=46)\end{array}$ & $\begin{array}{c}N A- \\
(n=129)\end{array}$ & $p$-value \\
\hline \multicolumn{5}{|c|}{ Clinical characteristics at the index procedure } \\
\hline \multicolumn{2}{|l|}{ Age (years) } & $68.7 \pm 8.1$ & $68.2 \pm 9.6$ & 0.76 \\
\hline \multicolumn{2}{|l|}{ Male } & $31(67.4)$ & $95(73.6)$ & 0.42 \\
\hline \multicolumn{2}{|l|}{$\mathrm{BMI}\left(\mathrm{kg} / \mathrm{m}^{2}\right)$} & $23.7 \pm 3.7$ & $24.3 \pm 3.1$ & 0.27 \\
\hline \multicolumn{2}{|c|}{$\begin{array}{l}\text { Follow-up duration of OCT } \\
\text { (months) }\end{array}$} & $46.7 \pm 23.5$ & $32.3 \pm 20.9$ & 0.001 \\
\hline \multicolumn{2}{|c|}{ Diabetes mellitus } & $21(45.6)$ & $64(49.6)$ & 0.65 \\
\hline \multicolumn{2}{|c|}{ Hypertension } & $36(78.2)$ & $111(86.0)$ & 0.21 \\
\hline \multicolumn{2}{|c|}{ Dyslipidaemia } & $36(78.2)$ & $113(87.6)$ & 0.12 \\
\hline \multicolumn{2}{|c|}{ Current smoker } & $9(19.5)$ & $34(26.3)$ & 0.29 \\
\hline \multicolumn{2}{|c|}{ Haemodialysis } & $4(8.7)$ & $7(5.4)$ & 0.31 \\
\hline \multicolumn{2}{|c|}{ Previous coronary angioplasty } & $17(36.9)$ & 49 (37.9) & 0.90 \\
\hline \multicolumn{2}{|c|}{ Previous myocardial infarction } & $12(26.1)$ & $29(22.4)$ & 0.62 \\
\hline \multicolumn{2}{|c|}{$\begin{array}{l}\text { Previous coronary artery bypass } \\
\text { graft }\end{array}$} & $4(8.7)$ & $2(1.5)$ & 0.042 \\
\hline \multicolumn{2}{|c|}{ Ejection fraction } & $58.1 \pm 13.2$ & $59.6 \pm 8.3$ & 0.51 \\
\hline \multirow{2}{*}{$\begin{array}{l}\text { Angina } \\
\text { status }\end{array}$} & Stable & $35(76.1)$ & 107 (82.9) & \multirow[b]{2}{*}{0.31} \\
\hline & $\begin{array}{l}\text { Unstable/Acute } \\
\text { coronary syndrome }\end{array}$ & $11(23.9)$ & $22(17.1)$ & \\
\hline \multirow{5}{*}{$\begin{array}{l}\text { Medication } \\
\text { at the last } \\
\text { OCT } \\
\text { follow-up }\end{array}$} & Aspirin & $43(93.4)$ & $122(94.6)$ & 0.52 \\
\hline & Thienopyridine & $30(65.2)$ & $89(69.0)$ & 0.64 \\
\hline & Statin & $28(60.8)$ & $102(79.0)$ & 0.015 \\
\hline & ACE-I and/or ARB & $29(63.0)$ & $101(78.2)$ & 0.066 \\
\hline & Beta-blocker & $24(52.1)$ & $73(56.6)$ & 0.60 \\
\hline \multicolumn{2}{|c|}{$\begin{array}{l}\text { Mean duration of dual antiplatelet } \\
\text { therapy (months) }\end{array}$} & $21.8 \pm 20.0$ & $22.9 \pm 18.4$ & 0.74 \\
\hline \multicolumn{5}{|c|}{ Laboratory data at follow-up OCT } \\
\hline \multicolumn{2}{|c|}{$\mathrm{CRP}(\mathrm{mg} / \mathrm{dL})$} & $0.27 \pm 0.34$ & $0.11 \pm 0.20$ & 0.003 \\
\hline \multicolumn{2}{|c|}{ HDL cholesterol (mg/dL) } & $47.8 \pm 11.0$ & $46.0 \pm 12.1$ & 0.38 \\
\hline \multicolumn{2}{|c|}{ LDL cholesterol (mg/dL) } & $95.8 \pm 26.2$ & $83.9 \pm 22.2$ & 0.004 \\
\hline \multicolumn{2}{|c|}{ Triglyceride (mg/dL) } & $138.9 \pm 64.5$ & $118.1 \pm 47.8$ & 0.050 \\
\hline \multicolumn{2}{|c|}{ Fasting glucose plasma (mg/dL) } & $112.0 \pm 32.7$ & $111.5 \pm 35.7$ & 0.94 \\
\hline \multicolumn{2}{|l|}{$\mathrm{HbA1C}(\%)$} & $6.2 \pm 1.2$ & $6.3 \pm 1.1$ & 0.97 \\
\hline \multicolumn{2}{|c|}{ Creatinine (mg/dL) } & $1.45 \pm 1.68$ & $1.37 \pm 1.58$ & 0.77 \\
\hline \multicolumn{5}{|c|}{$\begin{array}{l}\text { Values are presented as mean } \pm \text { SD or absolute numbers (\%). } \\
\text { ACE-I: angiotensin-converting enzyme inhibitor; ARB: angiotensin II } \\
\text { receptor blocker; BMI: body mass index; CRP: C-reactive protein; HDL } \\
\text { cholesterol: high-density lipoprotein cholesterol; LDL cholesterol: } \\
\text { low-density lipoprotein cholesterol; NA: neoatherosclerosis; OCT: optical } \\
\text { coherence tomography }\end{array}$} \\
\hline
\end{tabular}

death. The representative TLR case of the patient with NA is shown in Moving image 1. The incidence of MACE was significantly higher in the NA + group. This was mainly driven by an increase in the rate of cardiac death and TLR (Table 4). Moreover, the incidence of stent thrombosis (definite/probable) was significantly higher in the NA+ group than in the NA- group (Table 4, Figure 4). In the univariate analysis, high CRP level, the presence of NA, and haemodialysis were significantly associated with an increased incidence of MACE, whereas statin use was associated with fewer clinical events. Multivariate analysis demonstrated that 
Table 2. Baseline lesion characteristics at the index procedure.

\begin{tabular}{|c|c|c|c|c|}
\hline \multicolumn{2}{|c|}{ Variable } & $\underset{(n=54)}{N A+}$ & $\begin{array}{c}\text { NA- } \\
(n=260)\end{array}$ & $p$-value \\
\hline \multicolumn{2}{|c|}{$\begin{array}{l}\text { Follow-up duration of OCT } \\
\text { (months) }\end{array}$} & $43.9 \pm 24.8$ & $34.9 \pm 21.3$ & 0.006 \\
\hline \multirow[t]{3}{*}{$\begin{array}{l}\text { Lesion } \\
\text { location }\end{array}$} & $\begin{array}{l}\text { Left anterior descending } \\
\text { artery }\end{array}$ & $20(37.0)$ & $98(37.7)$ & 0.84 \\
\hline & Left circumflex artery & 9 (16.6) & 51 (19.6) & \\
\hline & Right coronary artery & $25(46.3)$ & $111(42.7)$ & \\
\hline \multirow{2}{*}{$\begin{array}{l}\text { Lesion } \\
\text { type }\end{array}$} & Type A/B1 & $11(20.4)$ & $104(40.0)$ & \multirow{2}{*}{0.01} \\
\hline & Type B2/C & $43(79.6)$ & $156(60.0)$ & \\
\hline \multicolumn{2}{|c|}{ De novo lesion } & $49(90.7)$ & $241(92.7)$ & 0.40 \\
\hline \multicolumn{2}{|c|}{ Chronic total occlusion } & 7 (14.9) & $27(10.4)$ & 0.58 \\
\hline \multicolumn{2}{|c|}{ Thrombus } & $2(3.7)$ & $13(5.0)$ & 0.51 \\
\hline \multicolumn{2}{|c|}{ Bifurcation lesion } & $5(9.2)$ & $45(17.3)$ & 0.14 \\
\hline \multirow{4}{*}{$\begin{array}{l}\text { Type of } \\
\text { stent }\end{array}$} & Sirolimus-eluting stent & $25(46.2)$ & $124(47.7)$ & \multirow{4}{*}{0.78} \\
\hline & Paclitaxel-eluting stent & $15(27.8)$ & $52(20.0)$ & \\
\hline & Everolimus-eluting stent & $8(14.8)$ & $53(20.4)$ & \\
\hline & Bare metal stent & $6(11.1)$ & 31 (11.9) & \\
\hline \multicolumn{2}{|c|}{ Stent size $(\mathrm{mm})$} & $3.04 \pm 0.42$ & $3.02 \pm 0.41$ & 0.76 \\
\hline \multicolumn{2}{|c|}{ Stent length (mm) } & $25.7 \pm 9.9$ & $23.3 \pm 9.9$ & 0.12 \\
\hline \multicolumn{2}{|c|}{ Post-dilatation } & $24(44.4)$ & 135 (51.9) & 0.51 \\
\hline \multicolumn{2}{|c|}{ IVUS-guided PCI } & $39(72.2)$ & $202(77.7)$ & 0.39 \\
\hline
\end{tabular}

high CRP level, the presence of NA, and haemodialysis were independently associated with future adverse events (Table 5).

Based on the ROC analysis, the best cut-off value for CRP for predicting MACE was $0.055 \mathrm{mg} / \mathrm{dL}$, with a sensitivity of $61 \%$ and a specificity of $82.7 \%$ (AUC: $0.73,95 \%$ CI: $0.63-0.83$ ) (Figure 5A). MACE were more frequent in the presence of NA and with a CRP level $>0.055 \mathrm{mg} / \mathrm{dL}$ (Figure 5B).

\section{INCIDENCE OF NEOATHEROSCLEROSIS STRATIFIED BY STENT TYPES}

We analysed a total of 314 lesions (SES: 149, PES: 67, EES: 61, BMS: 37 ) by the follow-up OCT. In the BMS group, stent length was significantly shorter and stent size was larger than in the others (Appendix Table 2). In the SES and PES groups, NA occurred at a constant rate at each period while the earliest case with NA in the BMS group was observed 65.5 months after stent implantation (Figure 6). In the EES group, NA was observed in $13.1 \%(7 / 61$ lesions) between 12 and 36 months after stent implantation, while there were no data from 36 months after stenting in this study because we had no cases available for $>36$ months of follow-up OCT with long-term clinical follow-up.

\section{Discussion}

\section{CLINICAL IMPACT AND RISK FACTORS OF NEOATHEROSCLEROSIS}

Atherogenic changes within the neointima are considered to be one of the primary substrates for both late stent thrombosis and restenosis after stent placement $4,6,13-15$. Using pathological examinations, Nakazawa et al reported an early progression of NA in the neointima of DES cases compared with BMS cases ${ }^{3}$. Moreover, a recent OCT study demonstrated a relatively high incidence of lipid-laden neointima $(67 \%)$ in patients $>5$ years after BMS implantation ${ }^{4,6}$. However, limited evidence is available on the long-term clinical impact of NA detected by OCT. Lee SY et al reported that patients with NA had a higher rate of TLR and stent thrombosis, compared with those without $\mathrm{NA}^{7}$. Being in line with the previous study, the present study shows that patients with NA have a significantly higher incidence of cardiac death, TLR, stent thrombosis (definite/probable), and MACE during the follow-up period. Multivariate analysis showed that patients with NA had a significantly greater risk of developing TLR and MACE. These findings support the concept that the development of NA can be
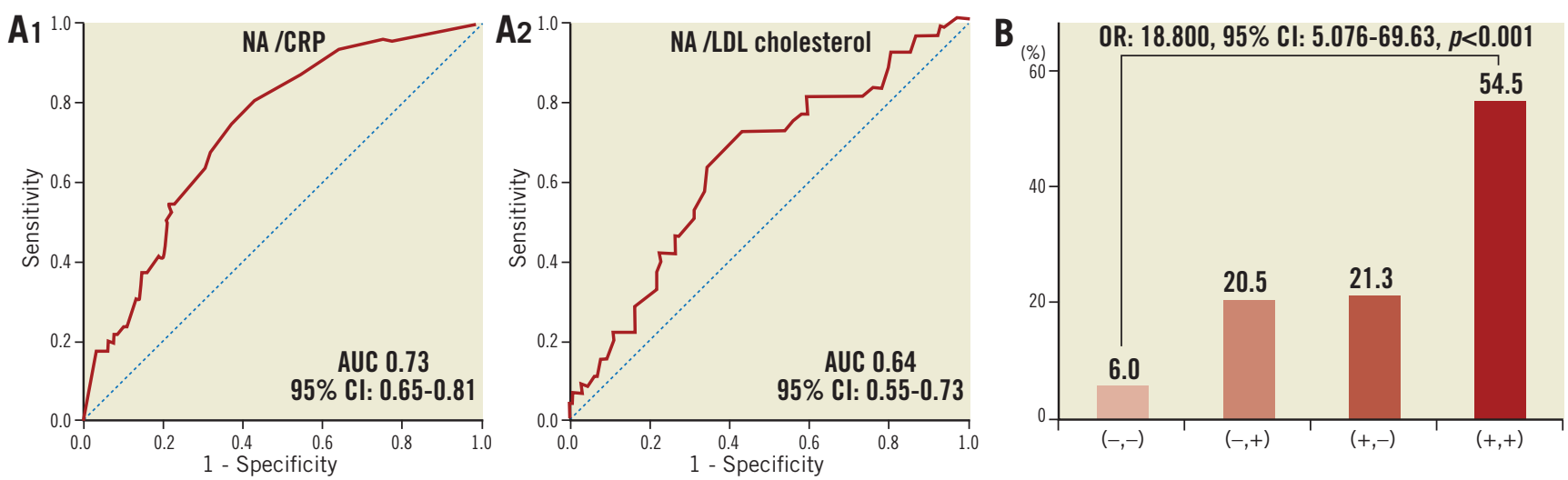

Figure 3. Diagnostic performance of $C R P$ and $L D L$ cholesterol for the presence of $N A$. A) ROC curves for the sensitivity and specificity of the association between the presence of $N A$ and $C R P$ level $\left(A_{1}\right)$ and LDL cholesterol level ( $\left.A_{2}\right)$. B) The prevalence of $N A$ stratified by the cut-off value of CRP and LDL cholesterol level. (-,-): patients with CRP $<0.055 \mathrm{mg} / \mathrm{dL}$ and LDL cholesterol $<86 \mathrm{mg} / \mathrm{dL}$; (-,+): patients with CRP $<0.055 \mathrm{mg} / \mathrm{dL}$ and LDL cholesterol $>86 \mathrm{mg} / \mathrm{dL}$; (+,-): patients with $C R P>0.055 \mathrm{mg} / \mathrm{dL}$ and LDL cholesterol $<86 \mathrm{mg} / \mathrm{dL} ;(+,+)$ : patients with $C R P>0.055 \mathrm{mg} / \mathrm{dL}$ and $L D L$ cholesterol $>86 \mathrm{mg} / \mathrm{dL}$ 
Table 3. Univariate and multivariate logistic regression analysis for the determinants of neoatherosclerosis.

\begin{tabular}{|c|c|c|c|c|c|c|}
\hline \multirow{2}{*}{ Variables } & \multicolumn{3}{|c|}{ Univariate } & \multicolumn{3}{|c|}{ Multivariate } \\
\hline & OR & $95 \% \mathrm{Cl}$ & $p$-value & OR & $95 \%$ Cl & $p$-value \\
\hline CRP & 1.022 & $1.009-1.035$ & 0.001 & 1.022 & $1.009-1.036$ & 0.001 \\
\hline LDL cholesterol & 1.021 & $1.006-1.035$ & 0.005 & 1.022 & $1.006-1.038$ & 0.008 \\
\hline Triglyceride & 1.007 & $1.001-1.013$ & 0.028 & & & \\
\hline Statin & 0.412 & $0.199-0.853$ & 0.017 & & & \\
\hline ACE-I/ARB & 0.502 & $0.240-1.053$ & 0.068 & & & \\
\hline
\end{tabular}

Table 4. Clinical events during follow-up.

\begin{tabular}{|l|c|c|c|} 
& $\begin{array}{c}\text { NA+ } \\
(\mathbf{n = 4 6 )}\end{array}$ & $\begin{array}{c}\text { NA- } \\
(\mathbf{n = 1 2 9 )}\end{array}$ & $\boldsymbol{p}$-value \\
\hline $\begin{array}{l}\text { Clinical follow-up duration after } \\
\text { stent implantation (months) }\end{array}$ & $54.2 \pm 27.3$ & $49.6 \pm 27.9$ & 0.34 \\
\hline MACE & $17(36.9)$ & $12(9.3)$ & $<0.001$ \\
\hline Death & $3(6.5)$ & $3(2.3)$ & 0.18 \\
\hline \multicolumn{1}{|c|}{ Cardiac cause } & $3(6.5)$ & $0(0.0)$ & 0.017 \\
\hline MI & $4(8.7)$ & $2(1.5)$ & 0.042 \\
\hline TLR & $14(30.4)$ & $10(7.7)$ & $<0.001$ \\
\hline $\begin{array}{l}\text { Stent thrombosis (definite/ } \\
\text { probable) }\end{array}$ & $3(6.5)$ & $0(0.0)$ & 0.017 \\
\hline
\end{tabular}

Values are presented as mean \pm SD or absolute numbers (\%).

MACE: major adverse cardiac events (composite of death, myocardial infarction and target lesion revascularisation); MI: myocardial infarction; TLR: target lesion revascularisation

one of the primary mechanisms of in-stent restenosis (ISR) and stent thrombosis, especially during the extended phase.

Despite a theoretical relationship between NA and late DES failure, information on the possible risk factors for NA progression after stenting is scarce. Yonetsu et al reported that, in addition to the stent type and the stent age, patient characteristics were associated with the presence of $\mathrm{NA}^{16}$, which is in accordance with the present study results. In addition, we further investigated possible risk factors concerning NA progression in more detail by using laboratory data. As a result, we found that high
LDL cholesterol and CRP levels were independently associated with NA after stent deployment, adding a new hypothesis to previously published data. More specifically, the risk for NA development increased 22 percent with each $0.1 \mathrm{mg} / \mathrm{dL}$ increase in CRP and 22 percent with a $10 \mathrm{mg} / \mathrm{dL}$ increase in LDL cholesterol level. Although ROC analysis showed a relatively low diagnostic accuracy for CRP and LDL cholesterol levels, the combined use of these two cut-off values increased the accuracy for predicting NA.

Measuring the CRP level is highly effective for global risk classification, independent of the LDL cholesterol level ${ }^{17}$. Previous studies have shown that statin therapy reduces LDL cholesterol and CRP levels in healthy subjects ${ }^{18}$, patients with stable coronary disease $^{19}$, and those with acute coronary syndrome ${ }^{20}$. Of note, a largescale Japanese registry clearly demonstrated that statin therapy at hospital discharge was associated with a significantly lower risk for late TLR $>1$ year after SES deployment, whereas statin use was not associated with early TLR after BMS or SES implantation $^{21}$. These findings suggest that there are different mechanisms underlying early and late ISR, which probably include smooth muscle cell proliferation for early ISR, and incomplete endothelial function with a newly formed atheroma within the neointima for late TLR. In a series of patients with very late stent thrombosis, Amabile et al demonstrated a tendency towards higher LDL cholesterol levels during thrombotic events in patients with NA ${ }^{22}$. According to previous and current studies, we currently speculate that it might be necessary for patients with coronary stents to be
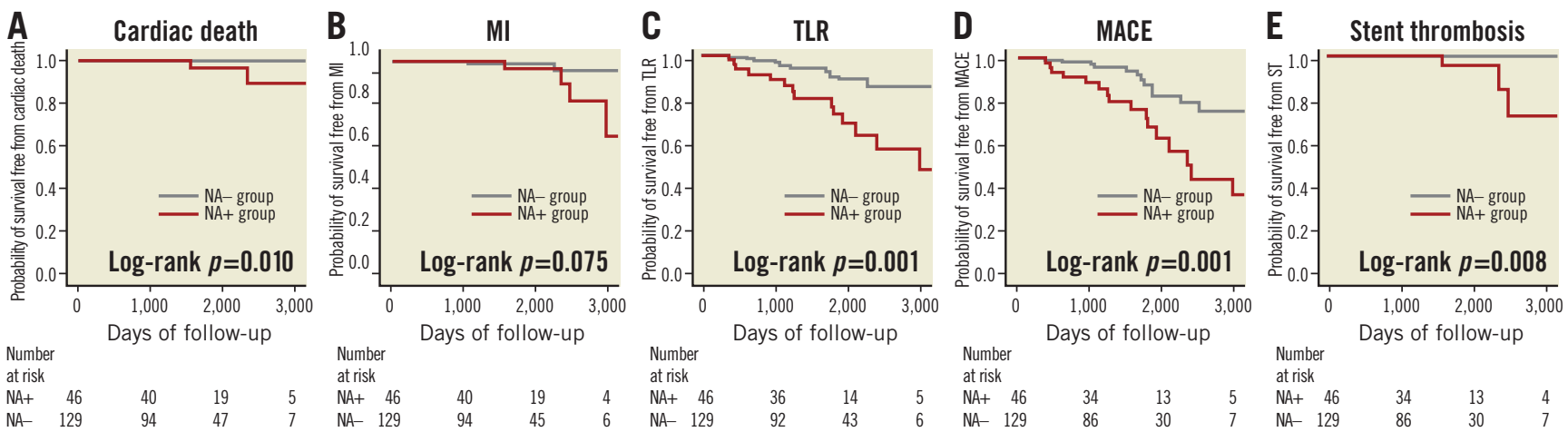

Figure 4. Kaplan-Meier survival curves stratified according to the presence or absence of NA. A) Cardiac death; B) MI; C) TLR; D) MACE; E) stent thrombosis. 
Table 5. Univariate and multivariate Cox proportional hazards regression analysis for the determinants of MACE.

\begin{tabular}{|c|c|c|c|c|c|c|}
\hline \multirow{2}{*}{ Variables } & \multicolumn{3}{|c|}{ Univariate } & \multicolumn{3}{|c|}{ Multivariate } \\
\hline & HR & $95 \% \mathrm{Cl}$ & $p$-value & HR & $95 \% \mathrm{Cl}$ & $p$-value \\
\hline Neoatherosclerosis & 3.370 & $1.606-7.073$ & 0.001 & 2.909 & $1.265-6.689$ & 0.012 \\
\hline CRP & 1.017 & $1.008-1.027$ & $<0.001$ & 1.016 & $1.004-1.028$ & 0.009 \\
\hline HDL cholesterol & 0.976 & $0.942-1.011$ & 0.178 & & & \\
\hline Haemodialysis & 3.494 & $1.388-8.798$ & 0.008 & 3.633 & $1.298-10.169$ & 0.014 \\
\hline Statin & 0.386 & $0.177-0.842$ & 0.017 & & & \\
\hline ACE-I/ARB & 0.522 & $0.246-1.109$ & 0.091 & & & \\
\hline
\end{tabular}

treated with optimal medical therapy including statins. A largescale prospective study is warranted to evaluate whether additional CRP and LDL cholesterol control will decrease NA progression and late clinical events.

\section{TIME COURSE OF NEOATHEROSCLEROSIS PROGRESSION}

In the present study, DES exhibited greater trends for atherosclerotic changes occurring at an earlier time point than BMS. The first DES case with NA was found at 12.2 months, while the first BMS case was found 5.5 years after stenting. A post-mortem pathological study demonstrated that atherogenic changes in neointima are found at $>4$ years after BMS placement ${ }^{23}$. Moreover, Hasegawa et al showed that, by using specimens obtained by directional coronary atherectomy, ISR lesions $>5$ years after stent placement are composed of atherosclerotic materials (cholesterol clefts, necrotising foam cells, and inflammatory cells ${ }^{24}$. These pathological findings are consistent with the current OCT findings that NA in BMS are observed only after extended follow-up ( $>5$ years). On the other hand, DES showed earlier initiation of NA in the present study. The early onset of atherosclerotic changes in DES rather than in BMS is probably due to drug effects, which are responsible for delayed arterial healing, incomplete endothelialisation as well

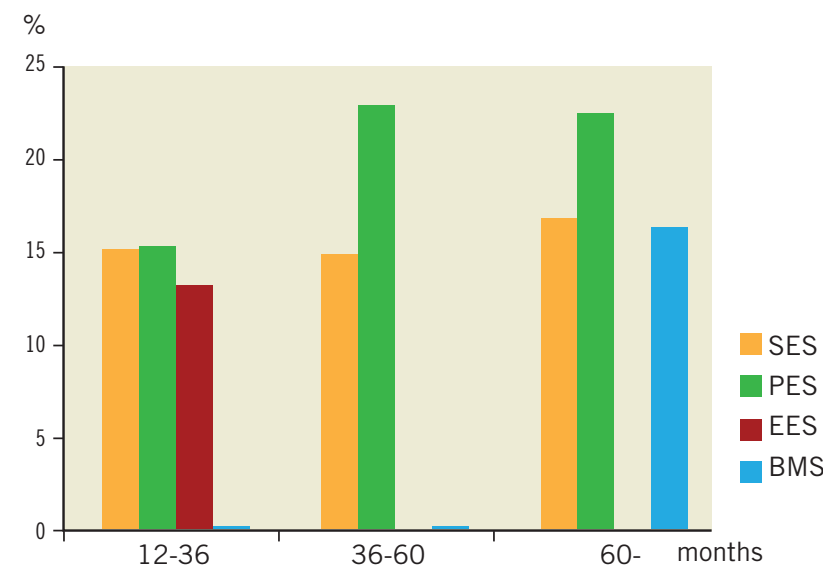

Figure 6. Cumulative incidence of atherosclerotic change with time after implantation of SES, PES and BMS. Both SES (yellow bars) and PES (green bars) show earlier onset of neoatherosclerosis and this occurred at a constant rate at each period as compared with BMS (blue bars). In the EES group (red bars), NA was observed in 13.1\% (7/61 lesions) between 12 and 36 months after stent implantation, while there were no data from 36 months after stenting in this study because we had no cases available for $>36$ months of follow-up OCT with long-term clinical follow-up.
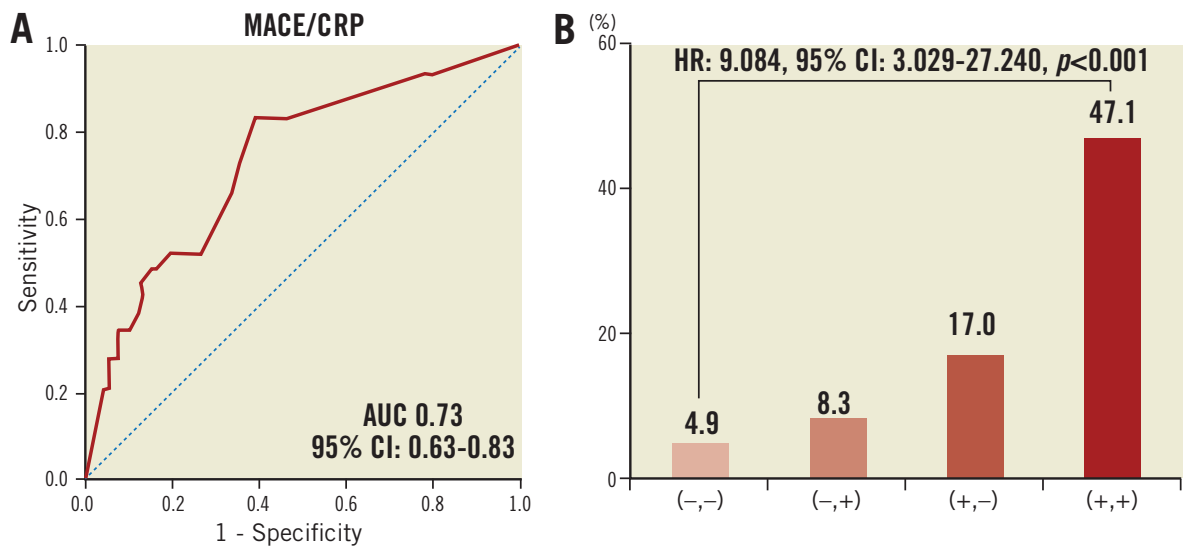

Figure 5. Importance of CRP and NA for MACE. A) ROC curve for the sensitivity and specificity of the association between the prevalence of $M A C E$ and CRP level. B) The incidence rate of MACE was classified into four groups according to the optimal cut-off value of CRP and the presence of $N A$. (-,-): patients with $C R P<0.055 \mathrm{mg} / \mathrm{dL}$ and the absence of $N A ;(-,+)$ : patients with $C R P<0.055 \mathrm{mg} / \mathrm{dL}$ and the presence of $\mathrm{NA}$; (+,-): patients with CRP>0.055 $\mathrm{mg} / \mathrm{dL}$ and the absence of $\mathrm{NA} ;(+,+)$ : patients with $C R P>0.055 \mathrm{mg} / \mathrm{dL}$ and the presence of $\mathrm{NA}$ 
as endothelial dysfunction. Long-term follow-up OCT data will be necessary to clarify the long-term incidence of NA progression in DES-treated lesions, especially those treated with PES and EES.

\section{Limitations}

This study has several limitations. First, this study was a single-centre study with a relatively small number of patients. Thus, a potential risk of patient selection bias exists. Second, we excluded patients with OCT examination $<1$ year after stent implantation, because the majority of NA progression occurs $>1$ year after stenting. Third, we did not validate the OCT findings with histological findings. Therefore, the regions identified as NA were not confirmed as containing atherosclerotic changes within the neointima. Fourth, in the present study, only $20 \%$ of patients underwent OCT before stenting. Therefore, the impact of baseline plaque characteristics on NA progression remains unclear. Angiographic analyses, however, showed that frequency of type B2/C lesions was independently associated with the presence of NA. Hence, local plaque characteristics (e.g., morphological complexity or plaque vulnerability) might affect NA progression. Finally, the variation in the duration of the follow-up period is a limitation in the assessment of NA. Therefore, it may be inappropriate to compare BMS and DES directly in terms of the timescale of NA. We, however, have 20 BMS-treated lesions which were subject to follow-up OCT at the earliest follow-up time point (12-36 months) out of a total of 37 BMS-treated lesions (54\%: 20/37). Interestingly, no lesion had NA among these 20 lesions, while around $15 \%$ of DES-treated lesions had NA at the earliest follow-up time point (12-36 months) (Appendix Table 2). Therefore, we currently consider that DES may exhibit greater trends for atherosclerotic changes occurring at an earlier time point than BMS. On the contrary, only $19 \%$ of DES-treated lesions (42/216) underwent follow-up OCT $>60$ months after stenting, and the majority of such lesions are treated with SES. In particular, we had no EES cases available for >36-month follow-up OCT with long-term clinical follow-up. Therefore, we consider that long-term follow-up OCT data will be necessary to clarify the long-term incidence of NA progression in DES-treated lesions, especially those treated with PES and EES. A sufficiently powered clinical study with a homogeneous follow-up period should be performed to address more adequately the true impact of NA on future clinical events.

\section{Conclusions}

In this OCT study, patients with NA had a significantly higher incidence of future cardiac death, TLR, stent thrombosis (definite/probable), and MACE during the follow-up period (mean $50.9 \pm 27.7$ months) after stenting. Patients with NA had 3.5 times the risk of TLR and 3.4 times the risk of MACE during the follow-up period, thus supporting the concept that NA can be one of the primary mechanisms of late stent failure. Considering that higher LDL cholesterol and CRP levels at follow-up were independent determinants of NA progression, it might be necessary for patients with coronary stents to be treated with optimal medical therapy including statins. A large-scale, randomised study will be warranted to elucidate whether early detection of NA and secondary prevention, especially with statin therapy, could be beneficial to improve the long-term outcome after coronary stenting.

\section{Impact on daily practice}

The presence of NA was independently associated with increased incidences of cardiac death, target lesion revascularisation, very late stent thrombosis, and MACE $>1$ year after stent placement, suggesting the need for careful clinical follow-up of patients with NA.

\section{Conflict of interest statement}

The authors have no conflicts of interest to declare.

\section{References}

1. Park SJ, Kang SJ, Virmani R, Nakano M, Ueda Y. In-stent neoatherosclerosis: a final common pathway of late stent failure. $J \mathrm{Am}$ Coll Cardiol. 2012;59:2051-7.

2. Otsuka F, Vorpahl M, Nakano M, Foerst J, Newell JB, Sakakura K, Kutys R, Ladich E, Finn AV, Kolodgie FD, Virmani R. Pathology of second-generation everolimus-eluting stents versus first-generation sirolimus- and paclitaxel-eluting stents in humans. Circulation. 2014;129:211-23.

3. Nakazawa G, Otsuka F, Nakano M, Vorpahl M, Yazdani SK, Ladich E, Kolodgie FD, Finn AV, Virmani R. The pathology of neoatherosclerosis in human coronary implants bare-metal and drugeluting stents. J Am Coll Cardiol. 2011;57:1314-22.

4. Kang SJ, Mintz GS, Akasaka T, Park DW, Lee JY, Kim WJ, Lee SW, Kim YH, Whan Lee C, Park SW, Park SJ. Optical coherence tomographic analysis of in-stent neoatherosclerosis after drug-eluting stent implantation. Circulation. 2011;123:2954-63.

5. Bezerra HG, Costa MA, Guagliumi G, Rollins AM, Simon DI. Intracoronary optical coherence tomography: a comprehensive review clinical and research applications. JACC Cardiovasc Interv. 2009;2:1035-46.

6. Takano M, Yamamoto M, Inami S, Murakami D, Ohba T, Seino Y, Mizuno K. Appearance of lipid-laden intima and neovascularization after implantation of bare-metal stents extended late-phase observation by intracoronary optical coherence tomography. $J \mathrm{Am}$ Coll Cardiol. 2009;55:26-32.

7. Lee SY, Shin DH, Mintz GS, Kim JS, Kim BK, Ko YG, Choi D, Jang Y, Hong MK. Optical coherence tomography-based evaluation of in-stent neoatherosclerosis in lesions with more than $50 \%$ neointimal cross-sectional area stenosis. EuroIntervention. 2013;9:945-51.

8. Matsumoto D, Shite J, Shinke T, Otake H, Tanino Y, Ogasawara D, Sawada T, Paredes OL, Hirata K, Yokoyama M. Neointimal coverage of sirolimus-eluting stents at 6-month followup: evaluated by optical coherence tomography. Eur Heart J. 2007;28:961-7.

9. Prati F, Regar E, Mintz GS, Arbustini E, Di Mario C, Jang IK, Akasaka T, Costa M, Guagliumi G, Grube E, Ozaki Y, Pinto F, 
Serruys PW; Expert's OCT Review Document. Expert review document on methodology, terminology, and clinical applications of optical coherence tomography: physical principles, methodology of image acquisition, and clinical application for assessment of coronary arteries and atherosclerosis. Eur Heart J. 2010;31:401-15.

10. Gonzalo N, Serruys PW, Okamura T, van Beusekom HM, Garcia-Garcia HM, van Soest G, van der Giessen W, Regar E. Optical coherence tomography patterns of stent restenosis. Am Heart J. 2009;158:284-93.

11. Cutlip DE, Windecker S, Mehran R, Boam A, Cohen DJ, van Es GA, Steg PG, Morel MA, Mauri L, Vranckx P, McFadden E, Lansky A, Hamon M, Krucoff MW, Serruys PW; Academic Research Consortium. Clinical end points in coronary stent trials: a case for standardized definitions. Circulation. 2007;115:2344-51.

12. Thygesen K, Alpert JS, White HD; Joint ESC/ACCF/AHA/ WHF Task Force for the Redefinition of Myocardial Infarction. Universal definition of myocardial infarction. $J$ Am Coll Cardiol. 2007;50:2173-95.

13. Lee CW, Kang SJ, Park DW, Lee SH, Kim YH, Kim JJ, Park SW, Mintz GS, Park SJ. Intravascular ultrasound findings in patients with very late stent thrombosis after either drug-eluting or bare-metal stent implantation. J Am Coll Cardiol. 2010;55:1936-42.

14. Kang SJ, Mintz GS, Park DW, Lee SW, Kim YH, Lee CW, Han KH, Kim JJ, Park SW, Park SJ. Tissue characterization of instent neointima using intravascular ultrasound radiofrequency data analysis. Am J Cardiol. 2010;106:1561-5.

15. Higo T, Ueda Y, Oyabu J, Okada K, Nishio M, Hirata A, Kashiwase K, Ogasawara N, Hirotani S, Kodama K. Atherosclerotic and thrombogenic neointima formed over sirolimus drug-eluting stent: an angioscopic study. JACC Cardiovasc Imaging. 2009;2: 616-24.

16. Yonetsu T, Kato K, Kim SJ, Xing L, Jia H, McNulty I, Lee H, Zhang S, Uemura S, Jang Y, Kang SJ, Park SJ, Lee S, Yu B, Kakuta T, Jang IK. Predictors for neoatherosclerosis: a retrospective observational study from the optical coherence tomography registry. Circ Cardiovasc Imaging. 2012;5:660-6.

17. Ridker PM, Rifai N, Rose L, Buring JE, Cook NR. Comparison of C-reactive protein and low-density lipoprotein cholesterol levels in the prediction of first cardiovascular events. $N$ Engl J Med. 2002;347:1557-65.

18. Ridker PM, Rifai N, Clearfield M, Downs JR, Weis SE, Miles JS, Gotto AM Jr; Air Force/Texas Coronary Atherosclerosis Prevention Study Investigators. Measurement of C-reactive protein for the targeting of statin therapy in the primary prevention of acute coronary events. N Engl J Med. 2001;344:1959-65.

19. Ridker PM, Rifai N, Pfeffer MA, Sacks FM, Moye LA, Goldman S, Flaker GC, Braunwald E. Inflammation, pravastatin, and the risk of coronary events after myocardial infarction in patients with average cholesterol levels. Cholesterol and Recurrent Events (CARE) Investigators. Circulation. 1998;98:839-44.

20. Ridker PM, Cannon CP, Morrow D, Rifai N, Rose LM, McCabe CH, Pfeffer MA, Braunwald E; Pravastatin or Atorvastatin
Evaluation and Infection Therapy-Thrombolysis in Myocardial Infarction 22 (PROVE IT-TIMI 22) Investigators. C-reactive protein levels and outcomes after statin therapy. $N$ Engl $J$ Med. 2005;352:20-8.

21. Natsuaki M, Nakagawa Y, Morimoto T, Ono K, Shizuta S, Furukawa Y, Kadota K, Iwabuchi M, Kato Y, Suwa S, Inada T, Doi O, Takizawa A, Nobuyoshi M, Kita T, Kimura T; CREDOKyoto PCI/CABG Registry Cohort-2 Investigators. Impact of statin therapy on late target lesion revascularization after sirolimus-eluting stent implantation (from the CREDO-Kyoto Registry Cohort-2). Am J Cardiol. 2012;109:1387-96.

22. Amabile N, Souteyrand G, Ghostine S, Combaret N, Slama MS, Barber-Chamoux N, Motreff P, Caussin C. Very late stent thrombosis related to incomplete neointimal coverage or neoatherosclerotic plaque rupture identified by optical coherence tomography imaging. Eur Heart J Cardiovasc Imaging. 2014;15:24-31.

23. Inoue K, Abe K, Ando K, Shirai S, Nishiyama K, Nakanishi M, Yamada T, Sakai K, Nakagawa Y, Hamasaki N, Kimura T, Nobuyoshi M, Miyamoto TA. Pathological analyses of long-term intracoronary Palmaz-Schatz stenting; Is its efficacy permanent? Cardiovasc Pathol. 2004;13:109-15.

24. Hasegawa K, Tamai H, Kyo E, Kosuga K, Ikeguchi S, Hata T, Okada M, Fujita S, Tsuji T, Takeda S, Fukuhara R, Kikuta Y, Motohara S, Ono K, Takeuchi E. Histopathological findings of new in-stent lesions developed beyond five years. Catheter Cardiovasc Interv. 2006;68:554-8.

\section{Supplementary data}

Appendix Table 1. Univariate and multivariate logistic regression analysis for determinants of neoatherosclerosis in lesions.

Appendix Table 2. Baseline lesion characteristics and incidence of neoatherosclerosis stratified by duration of stent implantation by using OCT examination.

Moving image 1. A 69-year-old man who received sirolimuseluting stent (SES) implantation $(3.5 * 23 \mathrm{~mm})$ in the proximal right coronary artery underwent follow-up coronary angiography (CAG) and optical coherence tomography (OCT) four years after stent implantation. His LDL cholesterol and C-reactive protein levels were $102 \mathrm{mg} / \mathrm{dL}$ and $0.08 \mathrm{mg} / \mathrm{dL}$, respectively. This OCT image shows neoatherosclerosis in the SES (Moving image 1A). Four years later, he underwent follow-up CAG because he felt chest discomfort from exertion. This CAG image shows stent occlusion in SES (Moving image 1B). We performed percutaneous coronary intervention for the lesion, and obtained the OCT image after coronary aspiration thrombectomy (Moving image 1C). This moving image shows neointima hyperplasia and thrombus in the stented segment, where neoatherosclerosis might exist.

\section{The supplementary data are published online at: http://www.pcronline.com/} eurointervention/108th_issue/224 